\title{
Same Day Upper and Lower Endoscopy Results in Patients Presenting with Nonspecific Abdominal Pain
}

\author{
Tülay Diken Allahverdi ${ }^{1}$, Barlas Sülü ${ }^{1}$ \\ ${ }^{1}$ Kafkas University Faculty of Medicine Department of General Surgery, Kars/Turkey \\ Received: 07 August 2015 accepted: 24 November 2015/ published online: 30 December 2015 \\ (C) Ordu University Institute of Health Science, Turkey, 2015
}

\begin{abstract}
Objective: The aim of this study was to evaluate the upper gastrointestinal endoscopy and colonoscopy results in patients who presented with abdominal pain and received a diagnosis of nonspecific abdominal pain following the examination and tests.

Methods: We included a total of 52 patients who presented at the emergency service between 01.01.2011 and 01.01.2012 with symptoms of abdominal pain and received a diagnosis of nonspecific abdominal pain following normal examination, routine blood and urine tests and ultrasound analysis. All patients underwent upper gastrointestinal endoscopy and colonoscopy on the same day. The results were evaluated and diagnoses made according to the endoscopy and pathology findings.

Results: There were $23(44.2 \%)$ males and 29 (55.8\%) females. The mean age was $54.5 \pm 15.3(23-86)$ years. A pathology was present on upper endoscopy in 47 (90.4\%) patients and lower endoscopy in 27 (51.9\%) patients. Comparison of the pathology rates for upper endoscopy and colonoscopy showed a significantly higher rate for upper endoscopy. The most common findings were chronic gastritis with upper endoscopy 13 males (25\%) and 17 (32.7\%) females, hemorrhoids with colonoscopy 10 males (19.2\%) and $12(23.1 \%)$ females. A pathology was present on both examinations in $25(48 \%)$ patients. Cancer was found in $7(13.5 \%)$ patients (6 gastric, 1 colon cancer). Helicobacter pylori was (+) in $53.8 \%$ of the cases. Conclusion: Same day upper and lower endoscopy in patients with nonspecific abdominal pain provided important results. However, we feel upper endoscopy should have priority when it is not possible to perform both investigations.

Key words: Abdominal pain, Endoscopy, Gastrit,

Address for correspondence/reprints:

Tülay Diken Allahverdi

Telephone number: +90 5066319651

E-mail: drtulaydiken@hotmail.com

DOI: $10.19127 / \mathrm{mbsjohs.89218}$

\section{Introduction}

Non-specific abdominal pain (NSAP) can be defined as a clinical picture where no cause can be found on examination or with investigations in patients who present to the hospital with abdominal pain and where the abdominal pain symptom gradually disappears by itself. Nonspecific abdominal pain can be an indicator of disorders that may require surgery or conservative treatment (Graff and Robinson, 2001).

It has been reported that abdominal pain is present in about $5-10 \%$ of the patients who present
\end{abstract}


to the emergency service and $35-40 \%$ of this group is diagnosed as non-specific abdominal pain that cannot be linked to any disease (Graff and Robinson, 2001; Lameris et al., 2007 ). The number of studies on NSAP is limited. The incidence of malignancy has been reported to be high with esophagogastroduodenoscopic and colonoscopic investigations in non-specific abdominal pain, especially in patients above the age of 50 (Graff and Robinson, 2001; Lameris et al., 2007). The approach to these patients, the analyses required and the follow-up durations could not be determined for sure as a result of these studies. We aimed to compare the results of same-day esophagogastroduodenoscopic and colonoscopic investigations in patients diagnosed with NSAP in our study.

\section{Materials and Methods}

The data of this descriptive study were obtained by investigating the files of 52 patients who had presented to the general surgery outpatients department with non-specific abdominal pain between 01 January 2011 and 01 January 2012. Local Ethics Committee approval (Kafkas University local Ethics Committee-80576354-05099) was received for the study. The patient history, physical examination findings, laboratory values (biochemical, complete blood count and urine), standing direct abdominal X-ray, and whole abdominal ultrasound results were available in the charts of the 52 patients studied. The signed information and consent form of the patients who had undergone upper GIS endoscopy and colonoscopy were also available in the charts. The patients were diagnosed by using upper GIS endoscopy and colonoscopy. No complication related to the procedure or any other procedures were reported in the charts.

\section{Results}

There were $23(44.2 \%)$ males and $29(55.8 \%)$ females. The mean age was $54.5 \pm 15.3$ years. Pathological findings were found with upper endoscopic investigation in $47(90.4 \%)$ and lower endoscopic investigation in 27 (51.9\%) patients. Pathological findings were present during both investigations in 25 patients. The most common finding was hemorrhoid with colonoscopy 19 (36.5\% / 7 males and 12 females) and chronic gastritis with upper GIS endoscopy 34 (65.4\% / 13 males and 21 females). We had 7 patients (13.5\%) were diagnosed with cancer ( 6 with upper GIS endoscopy and 1 with colonoscopy). Only 3 patients had no pathology on either investigation. The Helicobacter pylori rate was $53.8 \%$. The results of colonoscopic and upper GIS endoscopic investigations are presented in table 1-2.

Table 1 Upper GIS Endoscopic İnvestigation Results (Order Based on Percentage)

\begin{tabular}{lcr}
\hline Diagnosis & $\begin{array}{c}\text { Frequency- } \\
\text { Prevalence } \\
\text { (n) }\end{array}$ & (\%) \\
\hline Normal & 5 & 9.6 \\
Gastritis & 19 & 36.5 \\
Cancer & 6 & 11.5 \\
Esophagitis & 2 & 3.8 \\
Hiatal hernia & 1 & 1.9 \\
Gastritis+ Hiatal Hernia & 9 & 17.3 \\
Gastritis + Polyp & 1 & 1.9 \\
Gastritis + Esophagitis & 2 & 3.8 \\
Esophagitis + Hiatal & 3 & 5.7 \\
Hernia & & \\
Hiatal Hernia + Ulcer & 1 & 1.9 \\
Gastritis + Hiatal Hernia & 2 & 3.8 \\
+ Bulbitis & & \\
Gastritis + Esophagitis & 1 & 1.9 \\
+ Hiatal Hernia & & \\
Total & 52 & 9.6 \\
\hline
\end{tabular}

Table 2: Colonoscopic Investigation Results (Order Based on Percentage)

\begin{tabular}{lcc}
\hline Diagnosis & Prevalence & \% \\
\hline Normal & 25 & 48.1 \\
Diverticulosis & 7 & 13.5 \\
Polyp in colon, pseudopolyps + & 12 & 23.1 \\
Hemorrhoids & & \\
Cancer & 1 & 1.9 \\
Diverticulosis + Polyp in colon, & 2 & 3.8 \\
pseudopolyps + Hemorrhoids & & \\
Polyp in colon, pseudopolyps + & 2 & 3.8 \\
Hemorrhoids & & \\
Hemorrhoids + anal fissure & 2 & 3.8 \\
Diverticulosis + Polyp in colon + & 1 & 1.9 \\
Hemorrhoids & & \\
Total & 52 & 100.0 \\
\hline
\end{tabular}

\section{Discussion}

Patients who present to the emergency services and surgical outpatients with non-specific abdominal pain can create difficulties in terms of diagnosis and treatment. Patients diagnosed with NSAP constitute $30 \%-40 \%$ of the patients who present to these departments (Bavunoğlu and Şirin 2005; Özgüç et al., 2008; Stefanidis et al., 2009). 
The symptoms that can be found in patients presenting with non-specific abdominal pain are loss of appetite, nausea and vomiting. This patient group has been reported to consist of $60 \%$ females and $40 \%$ males (Aygencel et al., 2009). The female patient rate in our study was higher, similar to the literature. The most common reasons of abdominal pain are acute appendicitis, mesenteric lymphadenopathy, and nonspecific abdominal pain in young people and bowel obstruction, diverticular and hepatobiliary diseases in the elderly (Luken et al., 1990; Luken et al., 1993; Ağalar et al., 1999; Bavunoğlu and Şirin, 2005). Young adults make up the majority of the cases with non-specific abdominal pain. The NSAP rate was reported to be $32 \%$ under the age of 50 and $10 \%$ above the age of 50 by Kraemer et al. (2000). A rate of $60 \%$ was found in patients above the age of 50 in our study, in contrast to that reported in the literature. We believe that the reason is that young patients with decreasing symptoms refuse same-day upper GIS endoscopy and colonoscopy.

The symptoms and findings as well as laboratory evaluations, imaging methods and endoscopic methods are important in the diagnosis of these patients. Ultrasonography may help diagnose certain conditions in patients presenting with abdominal pain. However, it mostly provides negative signs in patients with abdominal pain of unknown cause. While some centers regard ultrasonography as sufficient for the diagnosis of the cause of the pain in patients with NSAP, other centers recommend abdominal tomography. However, it may not be possible to make a diagnosis even with other imaging methods. Abdominal computed tomography and laparoscopy are recommended routinely with the patients monitored 24 hours after discharge to diagnose patients with NSAP in certain studies (Özgüç et al., 2008). The radiation dose and cost of CT and the cost and risks of laparoscopy are the disadvantages of the two methods. We preferred to perform ultrasonography in our patients due to radiation of CT in our study. We used endoscopic methods as an alternative method to $\mathrm{CT}$ to avoid radiation and to laparoscopy to avoid an invasive procedure in patients with normal ultrasonography. Upper gastrointestinal endoscopy is recommended for patients with odynophagia, chest pain, vomiting, weight loss, epigastric burning symptoms and iron deficiency anemia in addition to abdominal pain, and colonoscopy is recommended for patients with anemia, hematochezia, chronic diarrhea, weight loss, and change in intestinal habits in addition to abdominal pain (Van Mook et al., 2001; Varadarajulu et al., 2005; Stray and Weberg, 2006; Harris et al., 2007). Major pathology was found in more than $50 \%$ of the patients evaluated with upper GIS endoscopy due to symptoms of abdominal pain, odynophagia, weight loss, and vomiting by Varadarajulu et al. (2005) and the authors recommended upper GIS endoscopy in patients with odynophagia, burning, and weight loss, especially when the patient is an elderly male. The most common etiology in children presenting with abdominal pain was reflux esophagitis with upper GIS endoscopy in the study conducted by Thakkar et al. (2007). It was emphasized in the multi-center study of Harris et al. (2007) that colonoscopy is required less commonly in patients with non-specific symptoms such as abdominal pain and diarrhea and that colonoscopy is important in the diagnosis of colorectal cancer if iron deficiency anemia and positive occult blood in the stool are found in elderly patients.

We found pathology in 47 patients who presented with NSAP through the esophagogastroduodenoscopic investigation and in 27 patients through the colonoscopic investigation. We also made a diagnosis that could cause abdominal pain in 47 patients with esophagogastroduodenoscopy and 25 patients with colonoscopy. We were able to diagnose more patients with esophagogastroduodenoscopy than with colonoscopy, similar to other studies (Van Mook et al., 2001; Varadarajulu et al., 2005; Stray and Weberg, 2006; Harris et al., 2007; Thakkar et al., 2007). The patients were treated in accordance with the diagnoses. No other pathology was found with 1 year of follow-up. The NSAP group of course consists of patients with abdominal pain where the cause cannot be found by imaging methods and the symptoms mostly decrease by themselves with observation. Whether the diagnoses made with endoscopy in this patient group are definite is controversial. However, endoscopic methods may still be appropriate to detect and simultaneously treat pathologies such as polyp, ulcer, and cancer. One must not forget that gastrointestinal malignancies can develop later on in $10 \%$ of NSAP patients over the age of 50 as reported by de Dombal (1988). Endoscopic methods should therefore not be ignored for the early diagnosis of cancer in patients with NSAP.

The biggest deficiency of our study was the small number of patients. 
We believe that endoscopic investigations of NSAP patients in studies conducted with large patient series can at least enlighten us regarding their importance in the early diagnosis of the disorders that may create a basis of cancer.

\section{Conclusion}

In conclusion, same-day upper and lower gastrointestinal endoscopic investigations in NSAP patients seem to be important in terms of aiding the diagnosis. We believe that upper GIS endoscopy should be preferred if it not possible to perform both investigations.

Informed Consent: Verbal informed consent was obtained from patients who participated in this study

Peer-review: Externally peer-reviewed.

Author Contributions: Concept-BS, DesignTDA, Supervision- TDA, Funding-BS, MaterialsBS, Data Collection and/or Processing- BS, Analysis and/or Interpretation- TDA, Literature Review-TDA, Writing- TDA, Critical ReviewTDA

Conflict of Interest: No conflict of interest was declared by the authors.

Financial Disclosure: The authors declared that this study hasn't received any financial support.

\section{References}

Ağalar F, Özdoğan M, Daphan ÇE, Topaloğlu S, Sayek İ. Akut karınla başvuran geriatrik hastalarda cerrahi tedavi ve sonuçları. Turkish Journal of Geriatrics 1999; 2: 1-4.

Aygencel G, Y1lmaz U, Karamercan M, Karamercan A, İlhan MN. Acil serviste karın ağrısını değerlendirme maliyeti. Gazi Tıp Dergisi 2009; 20: 7-12.

Bavunoğlu I, Şirin F. Akut cerrahi karını taklit eden cerrahi dışı nedenler. Türkiye Klinikleri Cerrahi Tip Bilimleri 2005; 10: 30-35.

de Dombal FT. The OMGE acute abdominal pain survey. Progress report, 1986. Scand J Gastroenterol Suppl 1988; 144: 35-42.

Graff LG, Robinson D. Abdominal pain and emergency department evaluation. Emerg Med Clin North Am 2001; 19: 123-36.

Harris JK, Froehlich F, Gonvers JJ, Wietlisbach V, Burnand B, Vader JP. The appropriateness of colonoscopy: a multi-center, international, observational study. Int $\mathbf{J}$ Qual Health Care 2007; 19: 150-7.
Kraemer M, Franke C, Ohmann C, Yang Q. Acute Abdominal Pain Study Group. Acute appendicitis in late adulthood: incidence, presentation, and outcome. Results of a prospective multicenter acute abdominal pain study and a review of the literature. Langenbecks Arch Surg 2000; 385: 470-81.

Lameris W, Randen A, Dijkdraaf M, Bossuyt P, Stoker J, Boermeester M. Optimization of diagnostic imaging use in patients with acute abdominal pain (OPTIMA): Design and rationale. BMC Emergency Medicine 2007; 7: 9.

Luken TW, Emerman E, Effron D. The natural history and clinical findings in undifferentiated abdominal pain. Ann Emerg Med 1993; 22: 690-6.

Luken TW, McDonald PJ, Taylor I. Non-specific abdominal pain-an expensive mystery. J R Soc Med 1990; 83: 10-1.

Özgüç H, Çakın N, Duman U. Akut nonspesifik karın ağrılı olguların bir yıllık prognozları, semptom ve bulguların tanısal doğruluğu. Ulus Travma Acil Cerrahi Derg 2008; 14: 118-24.

Stefanidis D, Richardson WS, Chang L, Earle B, Fanelli RD. The role of diagnostic laparoscopy for acute abdominal conditions: an evidencebased review. Surg Endosc 2009; 23: 16-23.

Stray N, Weberg R.A. Prospective study of same day bi-directional endoscopy in the evaluation of patients with occult gastrointestinal bleeding. Scand J Gastroenterol 2006; 41: 844-50.

Thakkar K, Gilger MA, Shulman RJ, El Serag HB. EGD in children with abdominal pain: a systematic review. Am J Gastroenterol 2007; 102: 654-61.

Van Mook WN, Bourass-Bremers IH, Bos LP, Verhoeven HM, Engels LG. The outcome of esophagogastroduodenoscopy (EGD) in asymptomatic outpatients with iron deficiency anemia after a negative colonoscopy. Eur $\mathbf{J}$ Intern Med 2001; 12: 122-126.

Varadarajulu S, Eloubeidi MA, Patel RS, Mulcahy HE, Barkun A, Jowell P, Libby E, Schutz S, Nickl NJ, Cotton PB. The yield and the predictors of esophageal pathology when upper endoscopy is used for the initial evaluation of dysphagia. Gastrointest Endosc 2005; 61: 8048. 